\title{
CORRECTION
}

View Article Online

View Journal I View Issue

\section{Correction: High density and patternable growth of silicon, germanium and alloyed SiGe nanowires by a rapid anneal protocol}

Cite this: J. Mater. Chem. C, 2015

3, 8434

M. Bezuidenhout, ${ }^{a b}$ T. Kennedy, ${ }^{b}$ S. Belochapkine, ${ }^{b}$ Y. Guo, ${ }^{b}$ E. Mullane, ${ }^{\text {b }}$ P. A. Kiely ${ }^{a}$ and K. M. Ryan*b

DOI: $10.1039 / \mathrm{c} 5$ tc90134k

Correction for 'High density and patternable growth of silicon, germanium and alloyed SiGe nanowires

www.rsc.org/MaterialsC

by a rapid anneal protocol' by M. Bezuidenhout et al., J. Mater. Chem. C, 2015, 3, 7455-7462.

Ref. 49 of the manuscript has been updated as follows;

49 T. Kennedy, M. Bezuidenhout, K. Palaniappan, K. Stokes, M. Brandon and K. M. Ryan, ACS Nano, 2015, DOI: 10.1021/ acsnano.5b02528.

The Royal Society of Chemistry apologises for these errors and any consequent inconvenience to authors and readers.

${ }^{a}$ Department of Life Sciences, and Materials and Surface Science Institute, University of Limerick, Limerick, Ireland

${ }^{b}$ Materials and Surface Science Institute and Department of Chemical and Environmental Sciences, University of Limerick, Limerick, Ireland. E-mail: Kevin.m.ryan@ul.ie 